\title{
SPOLM2019
}

XIX SIMPÓSIO DE PESQUISA OPERACIONAL E LOGISTICA DA MARINHA

\section{ESTRUTURAÇÃO DA PROBLEMÁTICA DE DESENVOLVIMENTO DE PROJETOS DE CT\&I NAS INSTITUIÇÕES DE ENSINO SUPERIOR PÚBLICAS UTILIZANDO UMA MULTIMETODOLOGIA}

\author{
Ademilton Grassiane dos Santos \\ Instituto Tecnológico de Aeronáutica - ITA \\ Praça Mal. do Ar Eduardo Gomes, 50 - São José dos Campos - SP \\ ademilton@ita.br \\ Adriana Martins Ribeiro \\ Instituto de Aeronáutica e Espaço - IAE \\ Praça Mal. do Ar Eduardo Gomes, 50 - São José dos Campos - SP \\ adrianaamr@fab.mil.br \\ Amanda Cecília Simões da Silva \\ Instituto Tecnológico de Aeronáutica - ITA \\ Praça Mal. do Ar Eduardo Gomes, 50 - São José dos Campos - SP \\ amandaac@ita.br \\ Mischel Carmen Neyra Belderrain \\ Instituto Tecnológico de Aeronáutica - ITA \\ Praça Mal. do Ar Eduardo Gomes, 50 - São José dos Campos - SP \\ carmen@ita.br
}

\begin{abstract}
RESUMO
Este artigo apresenta a aplicação de uma multimetodologia para estruturação de problemas composta por Soft Systems Methodology (SSM) e Strategic Options Development and Analysis (SODA) envolvendo desenvolvimento de projetos de Ciência, Tecnologia e Inovação (CT\&I) em uma Instituição Pública de Ensino Superior (IPES). Após a contextualização do problema, é apresentada a multimetodologia empregada para o estudo de caso, bem como sua aplicação e as dificuldades encontradas. Com a aplicação da multimetodologia, observou-se que uma das grandes vantagens de sua utilização foi que esta auxiliou o entendimento da situação problemática por meio de representações baseadas nos pontos de vistas das diversas partes interessadas, possibilitando consolidar uma visão holística da situação problemática estudada, bem como, aponta ações que podem auxiliar a transformar a situação problemática em uma situação ideal.
\end{abstract}

Palavra-chave: Métodos de Estruturação de Problemas; Multimetodologia; Gestão de Projetos. 


\begin{abstract}
This paper presents an application of a problem structuring multimethodology composed by Soft System Methodology (SSM) and Strategic Options Development and Analysis (SODA) involving the development of ST\&I projects in a higher-level public educational institution. After the contextualization of the problem, the multimethodology used in the study case is presented, and then an application of the same and as the difficulties encountered. After the application of the multimethodology, it was noted that one of its greatest advantages is that it helped to understand the problematic situation by concatenating points of view from different parts, consolidating a holistic view of the problematic situation, as well as pointing actions that can help transform a messy situation in an ideal situation.
\end{abstract}

Keywords: Problems Structuring Methods; Multimethodology, Project Management.

\title{
Como Citar:
}

SANTOS, A.G.; RIBEIRO, A.M.; SILVA, A.C.S.; BELDERRAIN, M.C.N. Estruturação da problemática de desenvolvimento de projetos de CT\&I nas instituições de ensino superior públicas utilizando uma multimetodologia. SIMPÓSIO DE PESQUISA OPERACIONAL E LOGÍSTICA DA MARINHA, Rio de Janeiro, 19., 2019, Anais [...]. Rio de Janeiro: Centro de Análises de Sistemas Navais, 2019.

\section{INTRODUÇÃO}

O desenvolvimento de projetos de CT\&I é um fator muito importante para as Instituições de Ensino Superior, pois possibilitam que os alunos e professores atuem em áreas inovadoras que estejam no avant guard no contexto tecnológico. Porém, projetos não acontecem sozinhos. É necessário o envolvimento de professores, dos alunos de graduação e pós-graduação, de professores de outras instituições de ensino, de centros de pesquisa, das indústrias de alta tecnologia, e do governo com suas políticas públicas e orçamentárias, todos e cada um deles com seus interesses e prioridades (CHIARINI e VIEIRA, 2012).

Entre as incertezas dos stakeholders quando se discute a questão de projetos de CT\&I dentro das Instituições Públicas Federais destacam-se projetos e, se estes deveriam ser estimulados ou não, e qual o seu impacto na parte acadêmica. Além disso, questiona-se também se estes projetos deveriam ter foco somente acadêmico ou em aplicações mais práticas ligadas a problemas do segmento industrial. Outrossim, há ainda debates sobre como viabilizar, operacionalizar e gerenciar projetos dentro das IPES de forma eficiente e eficaz. Porém, as mesmas estão preparadas para tal? Possuem em sua estrutura algum organismo que detenha o know-how e apoie no desenvolvimento e acompanhamento destes processos? Devem-se envolver fundações de apoio ou não? Como envolver os alunos?

Diante deste contexto, o presente trabalho objetivou compor uma multimetodologia de estruturação de problemas envolvendo Soft System Methodology (SSM) e Strategic Option Development and Analysis (SODA) para a estruturação e auxílio do entendimento da situação problemática apresentada.

Esta abordagem com multimetodologia permitiu concatenar pontos de vistas de diferentes partes interessadas consolidando uma visão holística da situação problemática estudada, bem como, apontar ações que possam auxiliar a transformar a situação problemática em uma situação ideal.

O trabalho está estruturado em quatro seções. A segunda seção apresenta brevemente a teoria sobre os métodos de estruturação de problemas com destaque para SSM SODA e Multimetodologia, a terceira seção apresenta a aplicação da multimetodologia e 
seus resultados, e a última apresenta as considerações finais.

\section{MÉTODOS DE ESTRUTURAÇÃO DE PROBLEMAS}

A estruturação de problemas é uma etapa do processo de tomada de decisão na qual são representados formalmente assuntos, problemas e situações, buscando interativamente propostas de soluções (não sendo obrigatória a sua resolução), sendo indispensável em casos onde seja necessária a incorporação de aspectos subjetivos nas decisões (EDEN, 1988).

Os métodos de estruturação de problema, do inglês Problem Structuring Methods (PSM), sugiram no final da década de 1970 e início da década de 1980 como resposta às limitações enfrentadas pelos tomadores de decisão que utilizavam métodos clássicos de Pesquisa Operacional, os quais por sua característica mais quantitativa partiam do pressuposto que o problema já estava estruturado e definido (MINGERS e ROSENHEAD, 2004; ROSENHEAD, 2006; ACKERMANN, 2012 e ROSENHEAD, 1996).

Existem diversos PSM disponíveis na literatura, sendo os mais citados, a Strategic Options Development and Analysis (SODA), a Soft Systems Methodology (SSM) e a Strategic Choice Approach (SCA) (MINGERS; ROSENHEAD, 2004).

\subsection{SSM - SOFT SYSTEMS METHODOLOGY}

A Soft Systems Methodology (SSM), foi desenvolvida por Peter Checkland em 1969 como uma forma de modelagem de processos organizacionais, a qual pode ser utilizada tanto para estruturação de problemas complexos, quanto na gestão de mudanças (CHECKLAND, 1981).

A Figura 1 mostra a metodologia de aplicação da SSM por Checkland (1981), a qual é dividida em 7 estágios: 1) Explorar a situação problemática; 2) Expressar a situação problemática; 3) Construir definições sucintas de sistemas relevantes; 4) Elaborar modelos conceituais; 5) Comparar os estágios 4 com 2; 6) Listar mudanças desejáveis e viáveis; e 7) Sugerir ações para transformar a situação problemática.

Figura 1 - Sete Estágios da SSM.

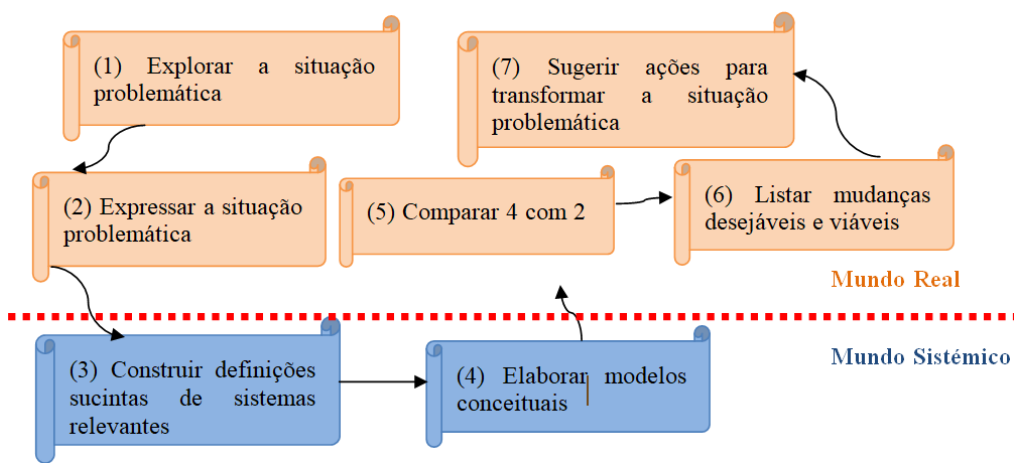

Fonte: Adaptado de (CHECKLAND, 1981).

\subsection{SODA - STRATEGIC OPTIONS DEVELOPMENT AND ANALYSIS}

A Strategic Options Development and Analysis (SODA) foi proposta por Colin Eden em 1988 para suprir a carência de métodos de Pesquisa Operacional adequados para facilitar os estágios iniciais de atendimento das necessidades dos clientes, que envolvem o entendimento por meio do diálogo e negociação da definição do problema a ser resolvido (EDEN, 1988).

A SODA é usada para tomadas de decisões em grupo em situações caracterizadas 
por incertezas e complexidades que não podem ser resolvidas por modelos quantitativos formais (EDEN, 1995).

A aplicação da SODA pode ser dividida em 3 etapas: 1) Seleção de atores e entrevistas; 2) Construção dos mapas SODA, e 3) Análise dos mapas SODA (ICHIHARA, 2015).

$\mathrm{Na}$ etapa 1 (seleção de atores e entrevistas), são identificados os atores (stakeholders) e realizadas as entrevistas individuais. Após a transcrição das entrevistas, são elaborados os mapas SODA individuais, os quais posteriormente são validados junto aos entrevistados (ACKERMANN et al., 1992).

$\mathrm{Na}$ etapa 2 (construção dos mapas SODA), os mapas SODA individuais são validados e após unificados em um mapa SODA único, o qual é denominado Mapa SODA Agregado. Este mapa é, então, apresentado aos stakeholders, que em conjunto irão discutir os constructos e as ligações entre eles a fim de que o mapa final gerado seja representativo para todos, considerando cada um dos mapas individuais deles. Este mapa é denominado Mapa Congregado.

Por fim, na etapa 3 (análise dos mapas SODA), é realizada a análise do mapa congregado a qual visa identificar as questões-chave a serem exploradas e as opções estratégicas envolvidas no caso estudado.

\subsection{MULTIMEDOLOGIA}

Multimetodologia é a combinação de mais de uma metodologia dentro de uma intervenção particular, podendo ser caracterizada pelo uso em conjunto de metodologias de Pesquisa Operacional (PO) hard com PO hard, PO hard com PO soft, ou PO soft com PO soft (MINGERS e GILL, 1997).

$\mathrm{Na}$ aplicação deste estudo de caso, a multimetodologia proposta foi utilizar o mapa SODA no estágio 3 da SSM (construção de definições sucintas dos sistemas relevantes), a fim de auxiliar a identificação dos sistemas relevantes e posteriormente nas transformações, e também no estágio 4 (elaboração dos modelos conceituais).

Ressalta-se que para a aplicação dos PSM é essencial uma adequada seleção de atores ou "partes interessadas", do inglês stakeholders, abordado na próxima seção.

\subsection{SELEÇÃO DE PARTES INTERESSADAS (STAKEHOLDERS)}

Um ponto comum nos PSM é a necessidade de representar os stakeholders no processo de identificação e solução de problemas. Existem vários métodos para a seleção de stakeholders, baseados em diferentes definições e aplicações (ICHIHARA, 2015).

Ackermann e Eden em 2011 propõem uma forma de identificar e classificar stakeholders, conforme a Figura 2.

Figura 2 - Identificação e classificação de stakeholders.

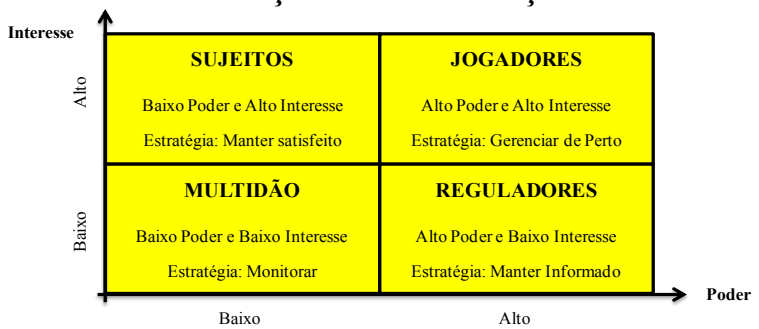

Fonte: Adaptado de (ACKERMANN E EDEN, 2011). 
Na classificação proposta por Ackermann e Eden (2011), os quadrantes superiores representam os stakeholders que possuem mais interesse na situação problemática, enquanto os inferiores representam os stakeholders que possuem menos interesse, embora possam apresentar alto poder para interferirem (ACKERMANN e EDEN, 2011). Para o presente estudo de caso, optou por envolver stakeholders de três dos quatro quadrantes (jogadores, sujeitos e reguladores) descartando-se o quadrante referente aos stakeholders de baixo poder e baixo interesse.

\section{APLICAÇÃO DA MULTIMETODOLOGIA}

\subsection{CONTEXTUALIZAÇÃO DO PROBLEMA}

Com a regulamentação da Lei de Inovação (Lei no 10.973/2004) e do "Marco Legal de Ciência, Tecnologia e Inovação" (Lei no 13.243/2016) por meio do Decreto 9.283/2018, as instituições públicas de ensino superior podem trabalhar de forma muito mais próxima às indústrias, através de alianças estratégicas que visam o desenvolvimento de projetos de cooperação que envolvam empresas, instituições de pesquisa científica e tecnológica (ICT) e entidades privadas sem fins lucrativos destinados às atividades de pesquisa e desenvolvimento, que objetivem a geração de produtos, processos e serviços inovadores e a transferência e a difusão de tecnologia. Além disso, segundo a nova legislação, os professores que trabalham em regime de dedicação integral e desenvolvam pesquisas dentro de empresas ou cujos laboratórios das instituições de ensino sejam usados pela indústria para o desenvolvimento de novas tecnologias, podem receber remuneração das indústrias por sua participação em projetos (BRASIL, 2004; BRASIL, 2016; BRASIL, 2018).

Dentro deste contexto, diversos são os fatores que podem colaborar com o incentivo ao desenvolvimento de projetos de CT\&I pelas instituições públicas de ensino superior, o que leva a discussões dentro das instituições sobre o que é o desenvolvimento de projetos de CT\&I do ponto de vista destas Instituições. Este é um assunto controverso, pois há professores que defendem que a função do professor é ensinar, e que isto deve ser feito em sala de aula. Por outro lado, há professores que defendem avidamente que os projetos de CT\&I podem ser ferramentas de trabalho extremamente úteis no processo de ensino junto aos alunos, por possibilitarem a aplicação da teoria em casos práticos, embora não seja obrigatória a realização dos mesmos pelos professores.

\subsection{SELEÇÃO DE STAKEHOLDERS}

Antes de se iniciar a aplicação da SODA, os autores realizaram uma reunião de alinhamento com o intuito de identificar quais os stakeholders que participariam do estudo de caso. Nesta reunião, a qual durou cerca de uma hora, avaliou-se os prós e contras de se envolver stakeholders de cada um dos quatro quadrantes, porém, devido à escassez de recursos e tempo optou-se por envolver apenas os stakeholders de três dos quatro quadrantes de maio impacto, que foram: jogadores, sujeitos e reguladores.

Seguem na Tabela 1 os stakeholders identificados. 
Tabela1 - Identificação dos stakeholders.

\begin{tabular}{l|c}
\hline \multicolumn{1}{c|}{ Função Exercida } & Identificação \\
\hline Professores/Pesquisadores das IPES SEM Projetos & PP-I \\
\hline Professores/Pesquisadores das IPES COM Projetos & PP-IP \\
\hline Professores/Pesquisadores das Universidades Parceiras & PP-U \\
\hline CEO das Agências e Fundações de Fomento & CEO-AF \\
\hline Entes Políticos do Governo & EPG \\
\hline Equipe de Fundações de Apoio & E-FA \\
\hline Gestor de Projetos do Escritório de Projetos da IPES & GP-EP \\
\hline CEO de Empresas e Indústrias & CEO-EI \\
\hline
\end{tabular}

Os stakeholders foram então classificados por meio do diagrama de poder e interesse, com base em conversas informais e experiência dos próprios facilitadores, conforme Figura 3.

Figura 3 - Classificação dos stakeholders.

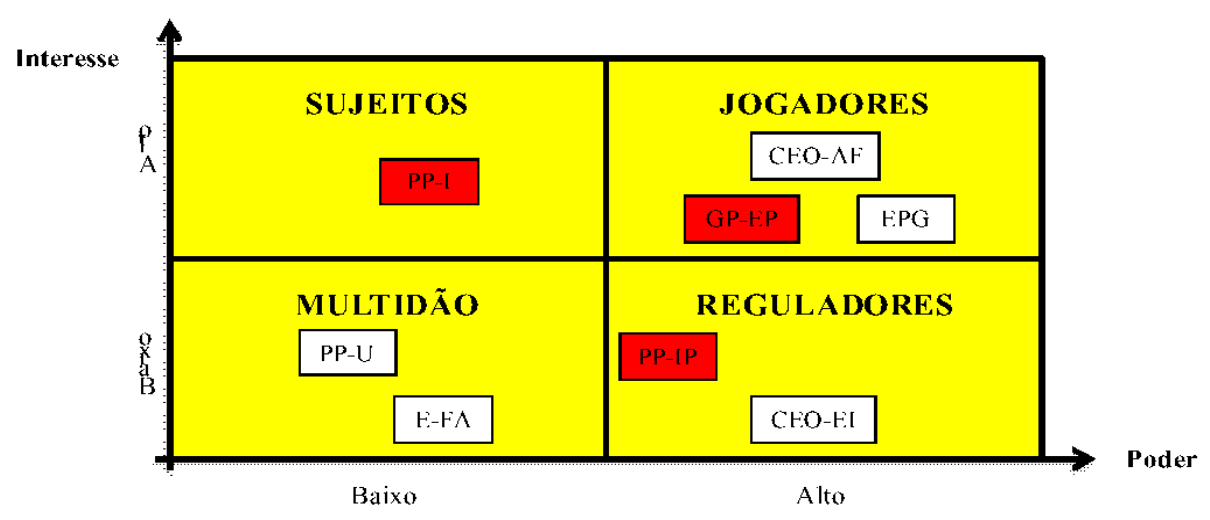

Principalmente devido à indisponibilidade de recursos para se realizar entrevistas externas a região de São Jose dos Campos, onde reside a equipe de estudo e se localiza a instituição pública de ensino superior analisada, foram consultados apenas os stakeholders assinalados em vermelho na Figura 3, uma vez que estes estão localizados na mesma região.

Desta forma, os stakeholders consultados foram:

- PP-I - Professor que não tem projetos com empresas/indústrias e nem projetos acadêmicos, mas deseja ter;

- GP-EP - Gestor de projetos do escritório de projetos da instituição, que tem interesse no aumento do desenvolvimento de projetos sejam junto às empresas/indústrias ou projetos acadêmicos e tem poder para aprovar estes projetos; e

- PP-IP - Professor com experiência em projetos acadêmicos e baixo interesse de projetos junto às empresas/indústrias.

\subsection{SSM E SODA}

\subsubsection{Estágio 1: Explorar a Situação Problemática}

Com base no áudio das entrevistas gravadas para a SODA, com dois professores da instituição pública estudada e um membro da equipe do escritório de projetos, foi possível 
capturar percepções diferentes sobre a situação problemática estudada, a qual envolve o desenvolvimento de projetos de CT\&I em instituição pública de ensino superior.

A situação problemática percebida pelos autores com base nos áudio gravados anteriormente foi a seguinte:

"Independentemente da carga de trabalho em sala de aula, existe a possibilidade dos professores atuarem em projetos de CT\&I com coparticipação dos alunos, os quais podem ter foco acadêmico ou serem de interesse da indústria. Além da sobrecarga de trabalho gerada, outros fatores também podem influenciar positiva ou negativamente o interesse dos professores em desenvolver projetos, tais como a necessidade de uma infraestrutura própria (tanto de pessoal quanto laboratorial), de apoio financeiro, de perfil dos professores quanto a pesquisa, de entendimento da burocracia envolvida no processo de apresentação de propostas e posterior condução dos projetos e prestação de contas, incerteza quanto ao sucesso, morosidade nos processos de aquisição para órgãos públicos, possibilidade de subsidiar bolsas de iniciação científica e pós-graduação e bolsas para os professores."

\subsubsection{Estágio 2: Expressar a Situação Problemática}

Com base nas informações coletadas no estágio anterior foi elaborada uma Figura Rica (Figura 4), a qual expressa a situação problemática percebida acerca do desenvolvimento de projetos de CT\&I na instituição pública de ensino superior.

Figura 4 - Figura Rica.

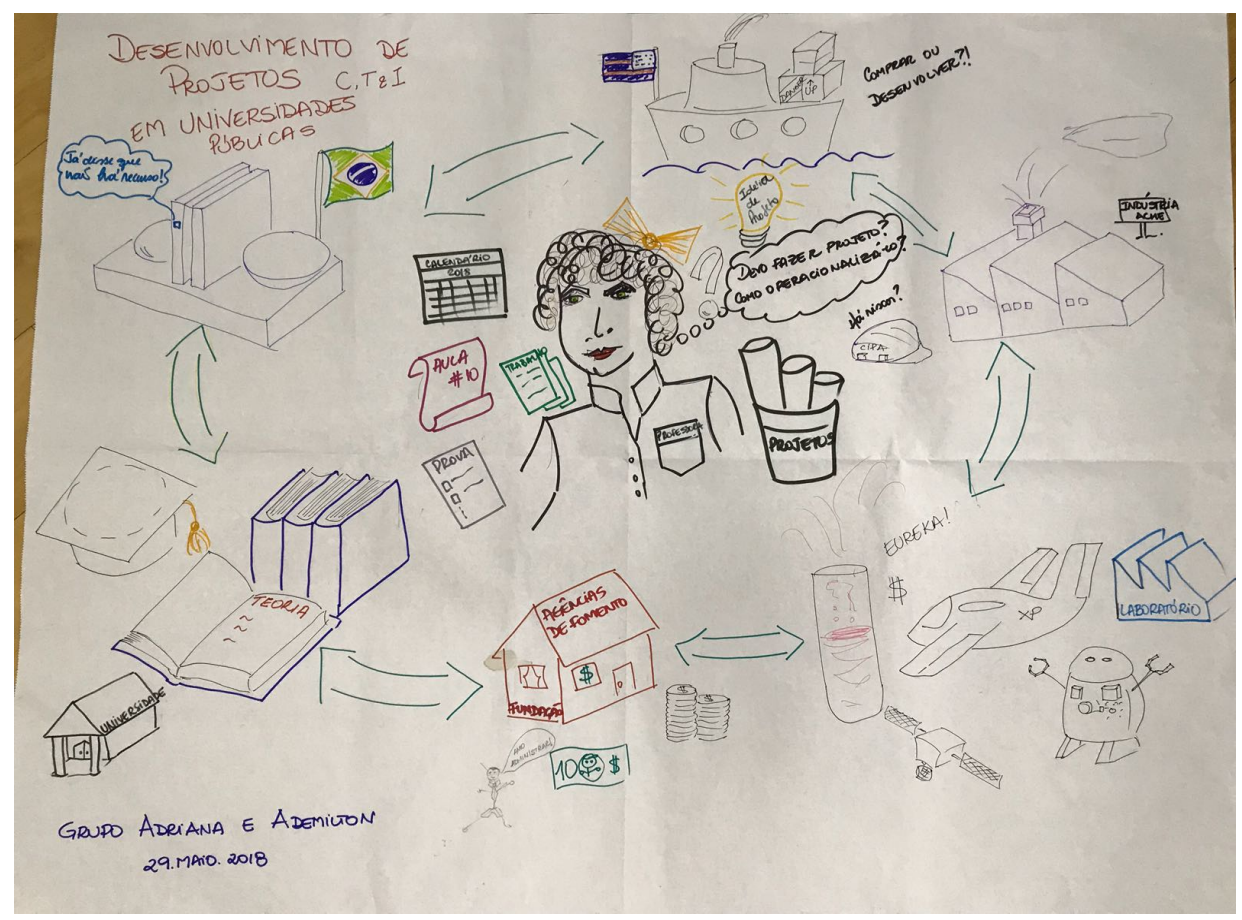

Ao centro da Figura Rica, encontra-se um professor(a) com suas responsabilidades acadêmica definidas, tais como calendário acadêmico, elaboração de aulas, correção de provas, e outras atribuições relativas a parte letiva. Em meio a estas atividades, diante de um insight para um projeto, o professor se questiona onde deve buscar apoio para o projeto, e como viabilizá-lo. O Quadro 1 mostra os interesses e questionamentos identificados pelos stakeholders dos principais recursos que na percepção destes devem ser envolvidos para apoiar a um projeto que estão representados na figura rica. 
Quadro 1 - Recursos e Questionamentos.

\begin{tabular}{|c|c|}
\hline Recursos & Interesses e Questionamentos \\
\hline Governo & $\begin{array}{l}\text { Como solicitar recursos? Há recursos disponíveis? O projeto é de } \\
\text { interesse nacional? O Ministério de Ciência, Tecnologia e Inovação } \\
\text { possui programas ou editais voltados para a área de conhecimento à qual } \\
\text { se pretende desenvolver a pesquisa? }\end{array}$ \\
\hline $\begin{array}{l}\text { Instituições } \\
\text { Públicas de } \\
\text { Ensino } \\
\text { Superior }\end{array}$ & $\begin{array}{l}\text { Como submeter um projeto? O projeto é de interesse da instituição de } \\
\text { ensino superior? Existe apoio ou orientações formalizadas sobre como } \\
\text { estruturar e viabilizar um projeto, seu acompanhamento na execução e } \\
\text { posterior encerramento? O processo é robusto ou está fragmentado? Onde } \\
\text { acessar o conhecimento? Quais parcerias já estão estabelecidas? }\end{array}$ \\
\hline $\begin{array}{l}\text { Órgãos de } \\
\text { Fomento e } \\
\text { Fundações de } \\
\text { Apoio }\end{array}$ & $\begin{array}{l}\text { Como solicitar recursos? Existem editais disponíveis ou recursos nas } \\
\text { agências de fomento? Para viabilização do projeto, deverá ter a } \\
\text { participação de uma fundação como gestora financeira, ou o projeto } \\
\text { poderá ser submetido diretamente pelo professor da Instituição Pública de } \\
\text { Ensino Superior? }\end{array}$ \\
\hline $\begin{array}{l}\text { Projetos de } \\
\text { Inovação / } \\
\text { Objetos de } \\
\text { Pesquisa }\end{array}$ & $\begin{array}{l}\text { As IPES possuem a infraestrutura adequada e equipe técnica suficiente } \\
\text { para o desenvolvimento do objeto da pesquisa? O objeto de pesquisa a ser } \\
\text { desenvolvido é de interesse da Instituição de Ensino Superior? Há } \\
\text { recursos de apoio com conhecimento específico para apoiar na execução? }\end{array}$ \\
\hline $\begin{array}{l}\text { Empresas / } \\
\text { Indústrias }\end{array}$ & $\begin{array}{l}\text { Como envolver empresas/indústrias? O objeto da pesquisa é de interesse } \\
\text { da indústria? A indústria possui recursos financeiros/infra estrutura e } \\
\text { programas de incentivo que possam ser aplicados no projeto? A empresa } \\
\text { tem funcionários que possam ser designados para ajudarem na execução } \\
\text { do projeto? }\end{array}$ \\
\hline $\begin{array}{l}\text { Aquisição de } \\
\text { itens chaves e } \\
\text { Equipamentos }\end{array}$ & $\begin{array}{l}\text { O projeto envolve necessidade de insumos ou produtos que só existam no } \\
\text { exterior? Deve-se desenvolver internamente, comprar no mercado } \\
\text { nacional ou importar? Qual a relação custo x benefício do projeto } \\
\text { principalmente quanto ao retorno para a sociedade? Tenho os } \\
\text { equipamentos necessários para desenvolver o projeto? }\end{array}$ \\
\hline
\end{tabular}

Com objetivo de esclarecer a situação problemática e construir as definições sucintas de sistemas relevantes, no próximo estágio utilizando a multimetodologia, foi elaborado um mapa SODA congregado.

\subsubsection{Estágio 3: Construir definições sucintas de sistemas relevantes}

a) Identificação dos Sistemas Relevantes

Neste estágio com base na Figura Rica e na percepção dos stakeholders, avaliando os interesses e questionamentos, foram identificados como prioritários 8 sistemas relevantes: Desconhecimento sobre como submeter projetos acadêmicos ou com a indústria, Identificação dos temas de projetos de interesse da instituição; Forma de quantificar o benefício tanto para a instituição de ensino quanto para a sociedade; Identificação da capacidade laboratorial e de recursos humanos que possam atuar em projetos; Desconhecimento das linhas de financiamentos e editais disponíveis; Desconhecimento dos processos de aquisição e se os recursos nacionais ou internacionais estão disponíveis; Desconhecimentos dos temas e ações priorizadas pelo governo; e Com quais outras instituições já se possui parceiras para desenvolver projeto.

Conforme proposto pelos autores, antes de se prosseguir com a identificação dos sistemas relevantes no mapa SODA, foi realizada a congregação dos mapas dos três 
stakeholders, sobre a mesma situação problemática, o qual é mostrado na Figura 5, elaborada no software Decision Explorer.

Desta forma, foi possível identificar os construtos dominantes e assim obter uma boa indicação sobre quais são os sistemas mais relevantes que poderiam ser abordados, marcados pela elipse vermelha na Figura 5 e abertos na Figura 6.

Figura 5 - Mapa Congregado dos stakeholders.

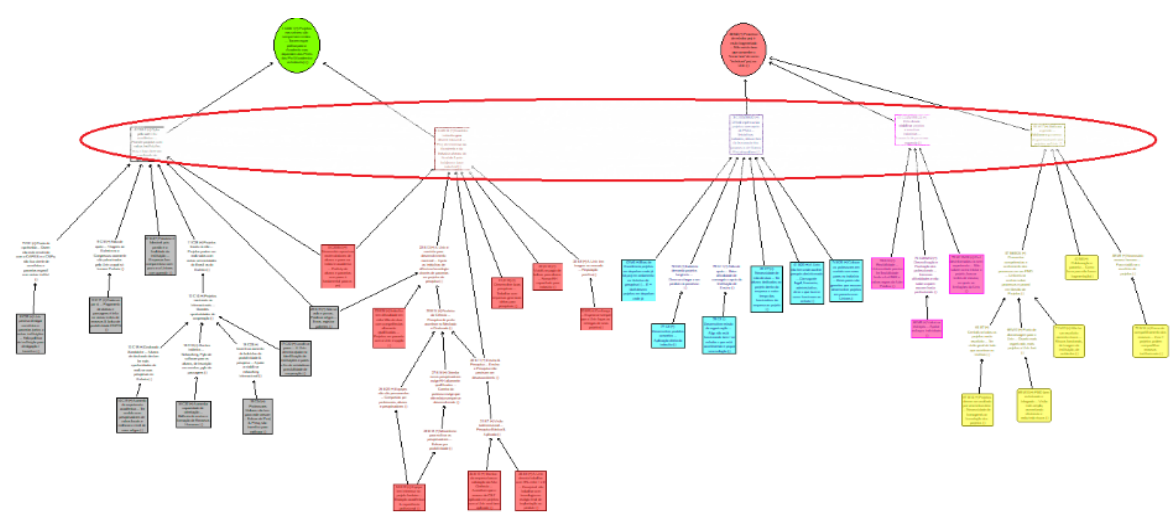

Figura 6 - Visualização dos constructos, do tipo cabeça e do tipo opções estratégicas.
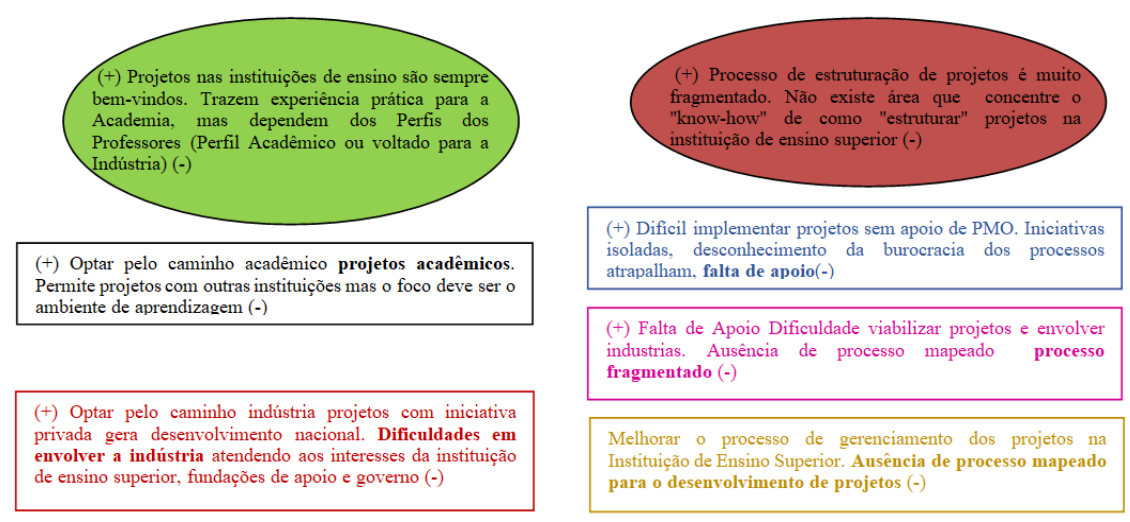

Por meio do Mapa Soda congregado, foi possível identificar 5 sistemas relevantes: Processo Fragmentado; Falta de Apoio (Escritório de Projetos); Projetos Acadêmicos; Dificuldades em envolver indústrias; e Ausência de processo mapeado para o desenvolvimento de projetos.

Considerando os 8 sistemas relevantes percebidos com a utilização da SSM e dos 5 sistemas relevantes obtidos com a utilização da SODA, para este estudo de caso, selecionaram-se dois dos sistemas relevantes, considerados pelos stakeholders como os mais representativos, pois englobam aspectos dos demais, tanto daqueles identificados na SSM quanto na SODA. São eles: Processo Fragmentado e Falta Apoio.

Além disso, estes dois sistemas relevantes impactam diretamente na capacidade de captação de projetos pela instituição de ensino superior, bem como em desenvolvê-los com maior eficiência e eficácia.

O sistema relevante "Processo Fragmentado", engloba aspectos do desconhecimento da burocracia de desenvolvimento de projetos de CT\&I na instituição de ensino superior, indefinição quanto a papéis e responsabilidades, processos não mapeados e formalizados, ausência de um programa de gestão do conhecimento em gerenciamento de 
projetos, e falta de um mecanismo de disseminação e uniformização do conhecimento relacionado ao desenvolvimento de projetos, seja acadêmico ou com a indústria.

O sistema relevante "Falta Apoio", engloba a ausência de um escritório de projetos atuante na identificação de editais, elaboração de propostas, acompanhamento e incentivo à execução eficiente e eficaz dos projetos, indefinição quanto à papéis e responsabilidades, processos não mapeados e formalizados, ausência de planos para capacitação da equipe do escritório de projetos nos processos sob sua responsabilidade e naqueles que possam gerar o aumento da capacidade de desenvolver projetos na instituição, apoio e suporte aos professores para a viabilização e acompanhamento da execução dos projetos, ausência de programas de incentivo e valorização dos professores e alunos, e ausência de estudos de custos para viabilização de estrutura mínima necessária para que o escritório de projetos possa atuar de maneira mais ampla.

\section{b) Identificação das Transformações, CATWOE e Definição Raiz}

Com base nos dois sistemas relevantes selecionados, foram construídas as definições sucintas dos mesmos, as quais são mostradas nos Quadros 2 e 3. Estas definições sucintas permitem uma melhor compreensão dos sistemas e da transformação desejada.

Para a construção das descrições sucintas foi feito uso da estruturação CATWOE. CATWOE é um acrônimo oriundo da língua inglesa que significa Clients, Actors, Transformation, Owners, Weltanschauung and Environment (clientes, partes interessadas, transformação, proprietários, visão de mundo e ambiente).

As transformações são os pontos que precisam ser transmutados a fim de se transformar algum aspecto indesejado da situação problemática em algo positivo. Já os CATWOE incorporam as transformações identificadas e auxiliam no levantamento de questões, cujas respostas levam a uma melhor compreensão das possíveis transformações. Por sua vez, a Definição raiz indica o que deve ser feito, por que isso deve ser feito, como deve ser feito e por quem deve ser feito.

Quadro 2 - Sistema Relevante (Processo Fragmentado).

T1- Processo de desenvolvimento de projetos de CT\&I fragmentado na instituição pública de ensino superior.

\begin{tabular}{|c|l|}
\hline C & Instituições Públicas de Ensino Superior, Alunos, Sociedade, Professores \\
\hline A & Professores, RH/Capacitação e Escritório de Projetos \\
\hline T & $\begin{array}{l}\text { Desconhecimento da burocracia de desenvolvimento de projetos de CT\&I. } \Rightarrow \\
\text { Conhecimento da burocracia de desenvolvimento de projetos de CT\&I. }\end{array}$ \\
\hline W & $\begin{array}{l}\text { Buscar soluções para aumentar a eficiência e eficácia na captação e } \\
\text { desenvolvimento de projetos }\end{array}$ \\
\hline O & Reitoria \\
\hline E & Resistência a mudança de cultura organizacional e aumento de carga de trabalho, \\
\hline
\end{tabular}

Definição Raiz: Um sistema que atende a Instituições Públicas de Ensino Superior, Alunos, Professores, e Sociedade operado por Professores, RH/Capacitação e Escritório de Projetos, que torna o desconhecimento da burocracia de desenvolvimento de projetos e CT\&I em conhecimento da burocracia desenvolvimento de projetos de CT\&I fragmentado na IPES e que busca soluções para a eficiência e eficácia na captação e desenvolvimento de projetos sob a responsabilidade da Reitoria e opera sob resistência a mudança de cultura organizacional e aumento de carga de trabalho. 
Quadro 3 - Sistema Relevante (Falta Apoio).

\begin{tabular}{|c|l|}
\hline T2 - Melhorar eficiência e eficácia da Equipe do Escritório de Projetos (Falta apoio) \\
\hline C & IPES, Fundação de Apoio, Alunos, Professores, Instituições Parceiras, Sociedade \\
\hline A & Escritório de Projetos e Professores \\
\hline T & $\begin{array}{l}\text { Atuação deficitária no apoio e incentivo aos professores na viabilização de novos } \\
\text { projetos } \Rightarrow \text { Estabelecer atuação de apoio e incentivo aos professores na } \\
\text { viabilização de novos projetos }\end{array}$ \\
\hline W & Aperfeiçoar o apoio prestados aos professores no desenvolvimento de projetos \\
\hline O & Reitoria e o Chefe do Escritório de Projetos \\
\hline E & $\begin{array}{l}\text { Falta recursos para capacitação e contratação de mão-de-obra capacitada para dar } \\
\text { apoio ao desenvolvimento de projetos }\end{array}$ \\
\hline $\begin{array}{l}\text { Definição Raiz: Um sistema que atende a IPES, Fundação de Apoio, Alunos, Professores, } \\
\text { Instituições Parceiras, Sociedade, operado pelo Escritório de Projetos e pelos Professores, } \\
\text { que realiza atuação deficitária no apoio e incentivo aos professores na viabilização de } \\
\text { novos projetos em estabelecer atuação de apoio e incentivo aos professores na } \\
\text { viabilização de novos projetos, para aperfeiçoar o apoio prestados aos professores } \\
\text { envolvidos com o desenvolvimento de projetos que está sob o domínio da Reitoria e do } \\
\text { Chefe do Escritório de Projetos e que opera sob falta de recursos para capacitação e } \\
\text { contratação de mão-de-obra capacitada para dar apoio ao desenvolvimento de projetos. }\end{array}$ \\
\hline
\end{tabular}

Dos sistemas relevantes destacam-se as transformações desejadas. Estas nortearão os modelos conceituais a serem elaborados a seguir.

\subsubsection{Estágio 4: Elaborar modelos conceituais}

Por meio dos CATWOEs elencados no estágio 3, e com o apoio do mapa SODA foram elaborados os modelos conceituais para a estruturação das atividades necessárias às transformações, os quais, segundo Georgiou (2012), também são denominados Sistema de Atividade Humana, do inglês, Human Activity System (HAS) (GEORGIOU, 2012).

A Tabela 2 apresenta o modelo conceitual para o sistema relevante Processo Fragmentado e a Tabela 3 apresenta os critérios de controle.

Tabela 2 - Modelos Conceituais para o Sistema Relevante Processo Fragmentado.

\begin{tabular}{c|l}
\hline $\mathbf{N}^{\mathbf{0}}$ & \multicolumn{1}{|c}{ Atividade } \\
\hline 1.1 & $\begin{array}{l}\text { Sistematizar as ações propostas de forma que possam ser acompanhadas e } \\
\text { mensuradas como se fosse um projeto. }\end{array}$ \\
\hline 1.2 & $\begin{array}{l}\text { Redefinir papéis e responsabilidades do Escritório de Projetos da Instituições } \\
\text { Públicas de Ensino Superior e dos Gerentes de Projeto (Professores) voltado para } \\
\text { eliminar as dúvidas sobre a fragmentação do conhecimento. }\end{array}$ \\
\hline 1.3 & $\begin{array}{l}\text { Identificar os processos ligados aos papéis e responsabilidades do Escritório de } \\
\text { Projetos da IPES e dos Gerentes de Projetos (Professores). }\end{array}$ \\
\hline 1.4 & $\begin{array}{l}\text { Definir planos de capacitação para padronização e uniformização do conhecimento } \\
\text { sobre processos associados ao desenvolvimento de projetos junto aos Professores. }\end{array}$ \\
\hline 1.5 & $\begin{array}{l}\text { Criar um programa de gestão de conhecimento (GC) que vise concentrar este } \\
\text { conhecimento em uma única área (escritório de projetos) e formas de difundi-lo. }\end{array}$ \\
\hline 1.6 & $\begin{array}{l}\text { Divulgar os documentos gerados para os processos mapeados e suas interfaces. } \\
1.7\end{array}$ Criar política para divulgação de convênios e parcerias juntos a outras instituições. \\
\hline 1.8 & $\begin{array}{l}\text { Criar mecanismos para auxiliar os professores na identificação de instituições e pares } \\
\text { a fim de estabelecer possibilidade de cooperação. }\end{array}$ \\
\hline
\end{tabular}


Tabela 3 - Critérios de Controle para o Sistema Relevante Processo Fragmentado.

\begin{tabular}{c|l|c}
\hline $\begin{array}{c}\text { Critérios de } \\
\text { Controle }\end{array}$ & \multicolumn{1}{|c}{ Questões } & Foco \\
\hline Eficácia & $\begin{array}{l}\text { Todos os processos foram identificados, detalhados e } \\
\text { suas interfaces mapeadas? }\end{array}$ & $\begin{array}{c}\text { Processos e seus } \\
\text { resultados }\end{array}$ \\
\hline Eficiência & $\begin{array}{l}\text { Qual o percentual da equipe prevista para os } \\
\text { treinamentos que efetivamente participaram deles? }\end{array}$ & Uso de recursos \\
\hline Efetividade & $\begin{array}{l}\text { Houve aumento na captação e desenvolvimento de } \\
\text { novos projetos, principalmente por professores sem } \\
\text { histórico de execução? }\end{array}$ & Estratégia \\
\hline
\end{tabular}

A Tabela 4 apresenta o modelo conceitual para o sistema relevante Falta de Apoio, e a Tabela 5 apresenta os critérios de controle.

Tabela 4 - Modelos Conceituais para o Sistema Relevante Falta de Apoio.

\begin{tabular}{c|l}
\hline $\mathbf{N}^{\mathbf{0}}$ & \multicolumn{1}{|c}{ Atividade } \\
\hline 2.1 & $\begin{array}{l}\text { Redefinir papéis e responsabilidades do Escritório de Projetos da IPES, dos Gerentes } \\
\text { de Projeto (Professores). }\end{array}$ \\
\hline 2.2 & $\begin{array}{l}\text { Identificar os processos ligados aos papéis e responsabilidades do Escritório de } \\
\text { Projetos da IPES, dos Gerentes de Projeto (Professores). }\end{array}$ \\
\hline 2.3 & $\begin{array}{l}\text { Elaborar estudo de custos para manter uma estrutura mínima de apoio e } \\
\text { acompanhamento dos projetos. }\end{array}$ \\
\hline 2.4 & $\begin{array}{l}\text { Elaborar um plano de ação para mapeamento dos processos e suas interfaces, bem } \\
\text { como, dos procedimentos ligados ao Desenvolvimento de Projetos na IPES. }\end{array}$ \\
\hline 2.5 & $\begin{array}{l}\text { Definir planos de capacitação para uniformização do conhecimento sobre formas de } \\
\text { apoio do Escritório de Projetos durante a estruturação, proposição e } \\
\text { desenvolvimento de projetos para a equipe do Escritório de Projetos. }\end{array}$ \\
\hline 2.6 & Criar programas motivacionais e de valorização para os alunos. \\
\hline 2.7 & $\begin{array}{l}\text { Criar um programa de motivação para os professores para os melhores projetos na } \\
\text { instituição. }\end{array}$ \\
\hline 2.8 & Criar competições que promovam o envolvimento dos alunos nos projetos. \\
\hline 2.9 & $\begin{array}{l}\text { Criar programas de premiações aos professores que mais colaboram com seus pares } \\
\text { compartilhando recursos e conhecimentos voltados ao desenvolvimento de projetos. }\end{array}$ \\
\hline
\end{tabular}

Tabela 5 - Critérios de Controle para o Sistema Relevante Falta de Apoio.

\begin{tabular}{c|l|c}
\hline $\begin{array}{c}\text { Critérios de } \\
\text { Controle }\end{array}$ & \multicolumn{1}{|c|}{ Questões } & Foco \\
\hline Eficácia & $\begin{array}{l}\text { Todos os processos do Escritório de Projetos foram } \\
\text { identificados, detalhados e suas interfaces mapeadas? }\end{array}$ & $\begin{array}{c}\text { Processos e } \\
\text { seus resultados }\end{array}$ \\
\hline Eficiência & $\begin{array}{l}\text { O Escritório possui um efetivo mínimo capacitado para } \\
\text { apoiar os Professores? }\end{array}$ & $\begin{array}{c}\text { Uso de } \\
\text { recursos }\end{array}$ \\
\hline Efetividade & $\begin{array}{l}\text { Houve aumento de professores e alunos engajados nos } \\
\text { projetos após a implementação dos projetos } \\
\text { motivacionais e de valorização? }\end{array}$ & Estratégia \\
\hline
\end{tabular}


A Figura 7 apresentam as atividades dos Sistemas Relevantes 1, à esquerda (a), e as do Sistema Relevante 2 (b), à direita utilizando-se o software CMaps. Foram assinaladas em verde as atividades complementares dos Modelos Conceituais que foram identificadas no Mapa SODA. Estes modelos conceituais foram então unidos para criar o modelo conceitual geral, mostrado na Figura 7(c) elaborada nos softwares CMaps e MS Paint, o qual auxilia no entendimento da situação problemática.

Figura 7 - As atividades dos Sistemas Relevantes 1 (a) e do Sistema Relevante 2 (b) e o Modelo Conceitual Geral (c).

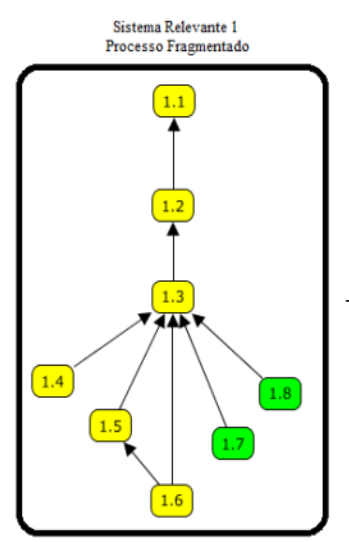

(a)

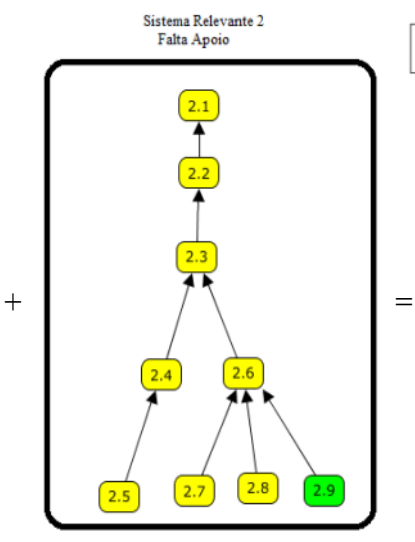

(b)

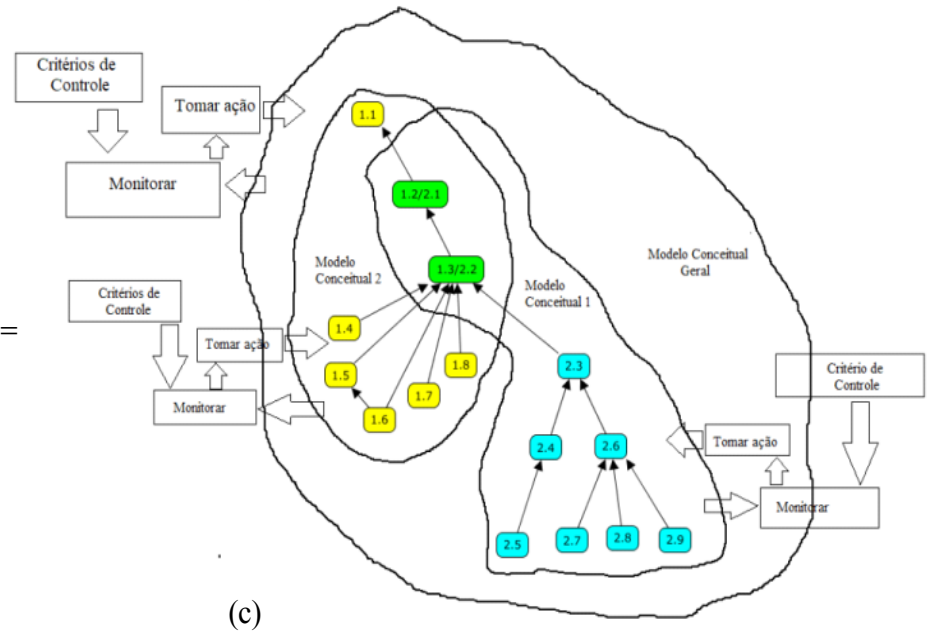

(c)

Ainda na Figura 7(c), foram assinalados em amarelo as atividades exclusivas do modelo conceitual 2; em azul, as atividades exclusivas do modelo conceitual 1; e, em verde, as comuns aos dois modelos conceituais.

\subsubsection{Estágio 5: Comparar os modelos conceituais com a situação problemática}

Neste estágio, compara-se a situação problemática apresentada no estágio 2 (situação problemática realidade) com os modelos de sistemas de atividade elaborados no estágio 4 (modelos conceituais).

Numa primeira análise detectou-se que as atividades 1.2 (2.1) e 1.3 (2.2) aparecem em ambos os Sistemas Relevantes 1 e 2. Percebe-se ainda que, com exceção das atividades 1.1 e 1.2 (2.1), todas as demais atividades são dependentes da atividade $1.3(2.2)$.

\subsubsection{Estágio 6: Listar mudanças desejáveis e viáveis}

Como desdobramento do estágio anterior, os autores realizaram uma análise das ações propostas quanto a sua inclinação a fim de identificar se as mesmas são sistemicamente desejáveis e culturalmente viáveis, a qual é mostrada na Tabela 6 . 
Tabela 6 - Ações sistematicamente desejáveis e culturalmente viáveis.

\begin{tabular}{c|l|c|c}
\hline $\mathbf{N}^{\mathbf{0}}$ & \multicolumn{1}{|c|}{ Atividades } & $\begin{array}{c}\text { Sistemicamente } \\
\text { Desejável }\end{array}$ & $\begin{array}{c}\text { Culturalmente } \\
\text { Viável }\end{array}$ \\
\hline 1.1 & Sistematizar as ações & $\checkmark$ & $\checkmark$ \\
\hline $1.2 / 2.1$ & Redefinir papéis e responsabilidades & $\checkmark$ & $\checkmark$ \\
\hline $1.3 / 2.2$ & Estabelecer processos ligados aos papéis & $\checkmark$ & $\checkmark$ \\
\hline 1.4 & Definir programa capacitação (professores) & $\checkmark$ & $\checkmark$ \\
\hline 1.5 & Criar programa Gestão do Conhecimento & $\checkmark$ & $\checkmark$ \\
\hline 1.6 & Publicar os documentos gerados & $\checkmark$ & $\checkmark$ \\
\hline 1.7 & Criar política para divulgação projetos & $\checkmark$ & $\checkmark$ \\
\hline 1.8 & $\begin{array}{l}\text { Criar mecanismos para auxiliar os } \\
\text { professores na identificação de instituições } \\
\text { e pares a fim de estabelecer cooperação }\end{array}$ & $\checkmark$ & $\checkmark$ \\
\hline 2.3 & Elaborar estudo de custos & $\checkmark$ & $\checkmark$ \\
\hline 2.4 & Elaborar plano mapeamento de processos & $\checkmark$ & $\mathbf{x}$ \\
\hline 2.5 & Definir capacitação (escritório de projetos) & $\checkmark$ & $\mathbf{x}$ \\
\hline 2.6 & $\begin{array}{l}\text { Criar programas motivacionais e de } \\
\text { valorização }\end{array}$ & $\checkmark$ & $\mathbf{x}$ \\
\hline 2.7 & Criar programa de motivação professores & $\checkmark$ & $\checkmark$ \\
\hline 2.8 & Criar competições para alunos & $\checkmark$ & $\checkmark$ \\
\hline 2.9 & $\begin{array}{l}\text { Criar programas premiações aos } \\
\text { professores que mais colaboram }\end{array}$ & & $\checkmark$ \\
\hline
\end{tabular}

\subsubsection{Estágio 7: Sugerir ações para a transformação da situação problemática}

Com base nas análises realizadas no estágio anterior sugerem-se ações vistas como essenciais para as melhorias, e que sejam sistemicamente desejáveis e culturalmente possíveis, as quais são apresentadas na Tabela 7 , com seus respectivos responsáveis, ou sejam aqueles com competência e autoridade para implementar as ações.

Tabela 7 - Ações para a melhoria da Situação Problemática.

\begin{tabular}{|c|c|c|}
\hline $\mathbf{N}^{\mathbf{0}}$ & Descrição & Responsável \\
\hline 1.1 & Sistematizar as ações & Escritório de Projetos \\
\hline $1.2 / 2.1$ & Redefinir papéis e responsabilidades & Reitoria \\
\hline $1.3 / 2.2$ & $\begin{array}{l}\text { Estabelecer processos ligados aos papéis e } \\
\text { responsabilidades }\end{array}$ & $\begin{array}{c}\text { Professores e Escritório } \\
\text { de Projetos }\end{array}$ \\
\hline 1.4 & Definir um programa de capacitação (professores) & $\begin{array}{c}\text { Equipe de } \\
\text { Capacitação/RH }\end{array}$ \\
\hline 1.5 & Criar um programa de Gestão do Conhecimento & Escritório de Projetos \\
\hline 1.6 & Divulgar os documentos gerados & Escritório de Projetos \\
\hline 1.7 & Criar política para divulgação de convênios e parcerias & Escritório de Projetos \\
\hline 1.8 & $\begin{array}{l}\text { Criar mecanismos para auxiliar os professores na } \\
\text { identificação de instituições e pares a fim de } \\
\text { estabelecer possibilidade de cooperação }\end{array}$ & Escritório de Projetos \\
\hline 2.3 & Elaborar estudo de custos & Escritório de Projetos \\
\hline 2.4 & Elaborar plano de mapeamento de processos & $\begin{array}{l}\text { Reitoria e Escritório de } \\
\text { Projetos }\end{array}$ \\
\hline 2.5 & Definir plano de capacitação (escritório de projetos) & $\begin{array}{c}\text { Equipe de } \\
\text { Capacitação/RH }\end{array}$ \\
\hline
\end{tabular}




\section{CONSIDERAÇÕES FINAIS}

Uma colaboração importante observada ao se comparar o uso do mapa SODA com SSM nos estágios 3 e 4, é que por meio do processo de elaboração dos mapas individuais e, posteriormente do mapa congregado, o escopo de entendimento da situação problemática foi expandido, e potencializou a sensação de se ter mapeado o problema em sua quase completude.

Durante a comparação entre abordagens SODA e SSM e de uma possível multimetodologia híbrida utilizando ambas as abordagens, percebeu-se que é extremamente relevante a aplicação combinada destas, pois explicitaram aspectos despercebidos da situação problemática que a aplicação de ambas abordagens aplicadas em separado não seriam capazes de identificar.

Além disso, no estágio 4, a agregação das informações retiradas do mapa SODA com as informações retiradas da Figura Rica permitiu se reforçar alguns aspectos em comum além de ampliar a percepção da situação problemática, as quais enriqueceram os modelos gerados.

Como este trabalho foi exploratório, e devido à limitação de recursos os autores não envolveram os stakeholders de todos os quadrantes e nem os externos à instituição de ensino superior objeto do estudo. Como sugestão de um possível trabalho futuro, recomenda-se o envolvimento de stakeholders de todos aos quadrantes, além daqueles considerados com alto interesse e poder mesmo que sejam externos a instituição, a fim de verificar se haveria enriquecimento tanto da Figura Rica quanto do mapa SODA e assim gerar novos desdobramentos nas definições raízes, o que permitiria uma visão ainda mais precisa das ações.

\section{AGRADECIMENTOS}

Este trabalho foi parcialmente apoiado pelo Conselho Nacional de Desenvolvimento Científico e Tecnológico - CNPq.

\section{REFERÊNCIAS BIBLIOGRÁFICAS}

[1] ACKERMANN, F. Problem Structuring methods 'in the Dock': Arguing the case of OR. European Journal of Operational Research. 219: 3 652-658, 2012.

[2] ACKERMANN, F.; EDEN, C. Strategic Management of Stakeholders: Theory and Practice, Long Range Planning, v. 44, n. 3, p. 179-196, 3 jun. 2011.

[3] ACKERMANN, F.; EDEN, C.; CROPPER, S. Getting Started with Cognitive Mapping. Tutorial paper, 7th Young OR Conference, 1992.

[4] BRASIL. Decreto $\mathbf{N}^{\mathbf{0}} \mathbf{9 . 2 8 3}$, de 7 de Fevereiro de 2018. Regulamenta a Lei $\mathrm{n}^{\mathbf{0}}$ 10.973, de 2 de dezembro de 2004, a Lei $\mathrm{n}^{\mathrm{o}} 13.243$, de 11 de janeiro de 2016, o art. 24, § $3^{\circ}$, e o art. 32, $\S 7^{\circ}$, da Lei ${ }^{\circ} 8.666$, de 21 de junho de 1993 , o art. $1^{\circ}$ da Lei $n^{\circ} 8.010$, de 29 de março de 1990, e o art. $2^{\circ}$, caput, inciso I, alínea "g", da Lei $\mathrm{n}^{\circ} 8.032$, de 12 de abril de 1990, e altera o Decreto $\mathrm{n}^{\mathrm{o}}$ 6.759, de 5 de fevereiro de 2009, para estabelecer medidas de incentivo à inovação e à pesquisa científica e tecnológica no ambiente produtivo, com vistas à capacitação tecnológica, ao alcance da autonomia tecnológica e ao desenvolvimento do sistema produtivo nacional e regional. Disponível em: http://www.planalto.gov.br/ccivil_03/_Ato2015-2018/2018/Decreto/D9283.htm. Acesso em: 2 jun. 2018. 
[5] BRASIL. Lei $\mathrm{N}^{\circ} \mathbf{1 3 . 2 4 3}$, de 11 de Janeiro de 2016. Dispõe sobre estímulos ao desenvolvimento científico, à pesquisa, à capacitação científica e tecnológica e à inovação e altera a Lei no 10.973, de 2 de dezembro de 2004, a Lei no 6.815, de 19 de agosto de 1980, a Lei no 8.666, de 21 de junho de 1993, a Lei no12.462, de 4 de agosto de 2011, a Lei no8.745, de 9 de dezembro de 1993, a Lei no 8.958, de 20 de dezembro de 1994, a Lei no8.010, de 29 de março de 1990, a Lei no 8.032, de 12 de abril de 1990, e a Lei no12.772, de 28 de dezembro de 2012, nos termos da Emenda Constitucional no 85, de26 de fevereiro de 2015. Disponível em: http://www.in.gov.br/web/guest/materia//asset_publisher/Kujrw0TZC2Mb/content/id/2 1155645/do1-2016-01-12-lei-no-13-243-de-11-de-janeiro-de-2016-21155131. Acesso em: 2 jul. 2018.

[6] BRASIL. Lei $\mathbf{N}^{\mathbf{0}} \mathbf{1 0 . 9 7 3}$, de 2 de Dezembro de 2004. Dispõe sobre incentivos à inovação e à pesquisa científica e tecnológica no ambiente produtivo e dá outras providências. Disponível em: https://www2.camara.leg.br/legin/fed/lei/2004/lei10973-2-dezembro-2004-534975-publicacaooriginal-21531-pl.html. Acesso em: 2 jun. 2018 .

[7] CHECKLAND, P. B. Systems Thinking, Systems Practice. 1. ed. Chichester: John, 1981.

[8] CHIARINI, T.; VIEIRA, K. P. Universidades como produtoras de conhecimento para o desenvolvimento econômico: sistema superior de ensino e as políticas de CT\&I. Revista Brasileira de Economia, 66(1), 117-132, 2012.

[9] EDEN, C. Cognitive mapping: A Review. European Journal of Operational Research, v. 36, n. 1, p. 1-13, 1988.

[10] EDEN, C. Strategic options development and analysis (SODA). In: Rational analysis revisited. Operational Research Society, Birmingham, 1995.

[11] GEORGIOU, I. Messing about in transformations: structured systemic planning for systemic solutions to systemic problems, European Journal of Operational Research, Vol. 223, No. 2, pp.392-406, 2012.

[12] ICHIHARA, R. C. S. Estruturação da Problemática de Sustentabilidade Financeira dos Laboratórios Metrológicos do CTGAS-ER. Dissertação (Mestrado Profissional em Produção), Instituto Tecnológico de Aeronáutica, São José dos Campos, 2015. Disponível em: http://www.fcmfmpep.org.br/site/sites/default/files/dissertacoes/turma2/Rafael_dp_08 8_2015.pdf. Acesso em: 2 jun. 2018.

[13] MINGERS, J. e; ROSENHEAD, J. Problem structuring methods in action. European Journal of Operational Research, v. 152, n. 3, p. 530-554, 2004.

[14] MINGERS, J.; GILL, A. Multimethodology: Theory and Practice of Combining Management Science Methodologies. Wiley, Chichester, 1997.

[15] ROSENHEAD, J. Past, present and future of problems structuring methods. Journal of Operational Research, 759-765, 2006.

[16] ROSENHEAD, J. What's the problem? An introduction to problem structuring methods. Interfaces, 117-131, 1996. 